\title{
O ENSINO DA LÍNGUA PORTUGUESA NA EDUCAÇÃO DE JOVENS ADULTOS DA APAE: UM OLHAR NAS PRÁTICAS PEDAGÓGICAS
}

\section{ARTIGO ORIGINAL}

SILVA, Lucimar de Cássia Fonseca ${ }^{1}$

SILVA, Fernanda Aparecida Oliveira Rodrigues ${ }^{2}$

SILVA, Lucimar de Cássia Fonseca. SILVA, Fernanda Aparecida Oliveira Rodrigues. O Ensino da Língua Portuguesa na Educação de Jovens Adultos da Apae: Um olhar nas práticas pedagógicas. Revista Científica Multidisciplinar Núcleo do Conhecimento. Ano 05, Ed. 12, Vol. 09, pp. 24-35. Dezembro de 2020. ISSN: 24480959, Link de acesso:https://www.nucleodoconhecimento.com.br/educacao/ensinoda-lingua

"Somos diferentes, mas não queremos ser transformados em desiguais. As nossas vidas só precisam ser acrescidas de recursos especiais" (Peça de teatro: Vozes da Consciência, $\mathrm{BH}$ )

\section{RESUMO}

1 Possui pós graduação no AEE- Atendimento Educacional Especializado pela FAVENI (2018); Pós-graduação em Metodologia de Ensino de Língua Portuguesa, Literatura e Artes pela UNISANTA (2018); Pós-graduação em Psicopedagogia Clínica e Institucional pela FAVENI (2019). É graduada em Letras- Língua Portuguesa pela Universidade Federal de Ouro Preto -UFOP- (2016). Atualmente faz $2^{\underline{a}}$ licenciatura na Educação Especial pela UNISANTA e Licenciatura em Língua Inglesa pela UFOP. ${ }^{2}$ Orientadora. Possui Doutorado (2013) e Mestrado (2008) em Educação - Educação, Cultura, Movimentos Sociais e Ações Coletivas - pela Universidade Federal de Minas Gerais - UFMG. Se especializou em Psicologia da Educação: ênfase em psicopedagogia preventiva pela PUCMinas (2001). É graduada em Pedagogia pela Faculdade de Filosofia Ciências e Letras de Macaé (1995). 
Historicamente, a Apae acolhe jovens e adultos com deficiência intelectual associada ou não a outras deficiências. Ao tornar-se escola, conquista dentro de um conjunto maior de ações, a Apae se oficializa como escola do sistema educativo e requer atenção à assimilação de informações necessárias para que seus educandos participem de um processo escolar significativo. O objetivo do trabalho é perceber como, de que forma e quais estratégias têm sido desenvolvidas no ensino da Língua Portuguesa para que educandos das turmas da Educação de Jovens e Adultos nesta escola interajam com a língua materna, considerando-a ferramenta necessária à escolarização. Em relação ao método de pesquisa, partiu-se da análise da Proposta Política Pedagógica da Apae de Mariana/MG, coletas de informações dadas pelos docentes e gestores. Das investigações, conclui-se que as adaptações das práticas pedagógicas nas Apaes e que a adequação curricular são inevitáveis, bem como a formação e capacitação do profissional docente no âmbito da sala de aula, cujos educandos necessitam do Atendimento Educacional Especializado e que, por isso, o corpo docente tem se validado de projetos e práticas mais contextualizadas e concretas nesta escola.

Palavras-chaves: Educação de Jovens e Adultos, Língua Portuguesa, Práticas Pedagógicas, deficiências.

\section{INTRODUÇÃO}

O objetivo deste trabalho é conhecer as práticas pedagógicas do ensino da Língua Portuguesa (LP) nas turmas da Educação de Jovens e Adultos (EJA), relacionadas aos educandos da Associação de Pais e Amigos dos Excepcionais (Apae) de Mariana (MG). A atenção está voltada para o ensino e a aprendizagem em contexto de déficit cognitivo dos aprendizes e os desafios que os profissionais da Educação Especial encontram ao trabalharem o Português em uma sala de aula com múltiplas especificidades. A escolha do tema surgiu pela nossa formação e pela percepção da necessidade de refletir sobre o ensino do Português oferecido aos educandos especiais, uma vez que isso requer, do docente, um trabalho dinâmico, com respeito às diferenças, valorização das competências e uma intervenção pedagógica adequada à cada educando. No âmbito da Apae, o Atendimento Educacional 
Especializado (AEE) torna-se imprescindível, visto que todos os educandos têm algum grau de deficiência seja ela física ou cognitiva.

Portanto, medidas para se tornarem concretas e que atendam ao requerimento do educando não podem destoar do seu conhecimento e da sua capacidade. Nesse sentido, nos propomos a refletir sobre alguns pontos que envolvem o processo de ensino/aprendizagem da LP nas turmas da EJA nessa escola, tais como: A escola tem materiais pedagógicos para trabalhar com os educandos do AEE? Como a equipe pedagógica desenvolve as atividades de aprendizagem? Encontra desafios? Quais? $O$ docente faz adequações no seu currículo pensando nos educandos do AEE? Quais? A pesquisa é de abordagem qualitativa. Ao ter um contato direto com a escola, fez-se uma análise da Proposta Político Pedagógica (PPP), bem como realizou-se conversas com regentes de aulas de LP e com gestores educacionais. Deste modo, coletadas as informações necessárias, foi possível citar algumas práticas educacionais da escola e mostrar algumas dificuldades com relação às adaptações das atividades. Antes disso, segue a contextualização sobre a implantação do ensino da EJA na Apae. Também serão apresentadas notas acerca dos direitos e propostas educacionais dos deficientes.

\section{BREVE RESGATE DA HISTÓRIA DAS APAES E DA IMPLATAÇÃO DA EJA NO ENSINO ESPECIAL}

A Apae surge a partir da mobilização dos pais e amigos de pessoas com deficiência, no início da segunda metade do século XX, que organizaram grande movimentação social em prol dos deficientes e fundaram as primeiras associações. Os objetivos das Associações eram garantir a assistência à saúde, a inclusão social, a educação e garantir os direitos da pessoa com deficiência intelectual e múltipla, uma vez que não havia políticas públicas e sociais que assegurassem a inserção dessas pessoas na sociedade. De acordo com a Federação Nacional das APAE:

essa mobilização social começou a prestar serviços de educação, saúde e assistência social a quem deles necessitasse, em locais que foram denominados como Associação de Pais e Amigos dos Excepcionais (Apae), constituindo uma rede de promoção e defesa de direitos das 
pessoas com deficiência intelectual e múltipla, que hoje conta com cerca de 250 mil pessoas com estes tipos de deficiência, organizadas em mais de duas mil unidades presentes em todo o território nacional (APAE BRASIL, 2020, p. 2).

Graças à todo esse movimento, iniciado por volta de 1950, e às incansáveis lutas ocorridas até os nossos dias, hoje é possível que pais de deficientes encontrem o apoio das escolas das Apaes por todo o território brasileiro. Diante disso, as pessoas com deficiência passaram a ter o direito à educação garantido pela Constituição da República Federativa do Brasil (1988) que traz as seguintes leis: o Art. $205^{\circ}$ define "a educação como um direito de todos, garantindo o pleno desenvolvimento da pessoa, o exercício da cidadania e a qualificação para o trabalho"; o Art. $206^{\circ}$ estabelece a "igualdade de condições de acesso e permanência na escola como um dos princípios para o ensino e garante, como dever do Estado, a oferta do atendimento educacional especializado, preferencialmente na rede regular de ensino"; e o Art. $208^{\circ}$ estabelece que é "dever do Estado garantir o direito à educação para todos".

Em 2001, após muitas controvérsias e discussões na Convenção da Guatemala (1999) $^{[3]}$, foi promulgado, no Brasil, o Decreto № 3.956/2001, afirmando que:

as pessoas com deficiência têm os mesmos direitos humanos e liberdades fundamentais que as demais pessoas, definindo como discriminação com base na deficiência toda diferenciação ou exclusão que possa impedir ou anular o exercício dos direitos humanos e de suas liberdades fundamentais (DECRETO N³956/2001).

Ainda assim, os jovens e adultos com deficiências não conseguiam acompanhar o período escolar da rede regular de ensino e concluir o Ensino Médio e, por isso, tinham que sair das escolas comuns e ir para outras entidades filantrópicas ou para as "escolas" das Apaes, bem como alguns educandos preferiam ir para as escolas especiais por se sentirem excluídos nas salas de aula, como ainda ocorre hoje, pela carência de acessibilidades ${ }^{[4]}$. Por consequência, dificilmente conseguiam trabalho ou ter plena e efetiva participação na sociedade junto aos seus pares. Tendo em vista todo esse cenário, era necessário assegurar a igualdade de oportunidades de ensino/aprendizagem destes jovens e adultos especiais, ou seja, fazer valer a lei e, no entanto, as políticas educacionais do estado implantaram a modalidade da EJA 
nas escolas especiais, seguindo o mesmo padrão de ensino das escolas comuns. $\mathrm{O}$ Estado tem o dever de garanti-la, conforme as orientações estabelecidas pelo Ministério da Educação (2016), que promulga o seguinte:

[...] a Lei no 13.005/2014, que institui o Plano Nacional de Educação - PNE, no inciso III, parágrafo $1^{\circ}$, do artigo $8^{\circ}$, determina que os estados, o Distrito Federal e os municípios garantam o atendimento às necessidades específicas na educação especial, assegurado o sistema educacional inclusivo em todos os níveis, etapas e modalidades. [...] O AEE é ofertado preferencialmente na rede regular de ensino, podendo ser realizado por meio de convênios com instituiç̃es especializadas, sem prejuízo do sistema educacional inclusivo (BRASIL, 2016, p. 34).

Logo, para cumprir o Decreto № 3.956/2001 e a Lei № 13.005/2014, citados anteriormente, em 2016, foi implantado, na Apae de Mariana, o currículo das escolas comuns na modalidade da EJA, que abrange os alunos do $6^{\circ}$ ao $9^{\circ}$ ano, e, assim, acolhe-se e escolariza-se, aproximadamente, 75 jovens e adultos com diferentes deficiências que não completaram o ensino fundamental nas escolas comuns.

\subsection{A EJA COMO MODALIDADE DA EDUCAÇÃO BÁSICA}

A modalidade da EJA institui-se como uma política educacional brasileira com o objetivo de atender os jovens acima de 15 anos, os adultos e os idosos que não conseguiram iniciar ou concluir o Ensino Fundamental e o Ensino Médio na idade satisfatória, por isso, nas turmas da EJA, há um público bastante diversificado no que toca às experiências de vida e aos processos cognitivos de aprendizagem. Essas diversidades presentes nas turmas das EJAs corroboram para que a profissão docente seja, ainda mais, desafiadora, porque ele está diante de sujeitos que demandam currículo e prática pedagógica de acordo com diferentes necessidades e especificidades, de modo que possam atingir e valorizar o conhecimento de cada um. Tendo essas características, as turmas das EJAs, nas escolas dos deficientes intelectuais e múltiplos, consequentemente, apontam para certas dificuldades e para a necessidade de adaptações curriculares, demandas essas que aparecem em uma maior proporção. 
Assim sendo, diante desse vislumbre, questiona-se: as propostas de ensino podem seguir os mesmos padrões de uma educação generalizada das escolas comuns? As práticas pedagógicas são pensadas de forma que sejam valorizados o conhecimento e as limitações de cada educando especial, aproveitando da habilidade de cada um a fim de construir a aprendizagem? O Ministério da Educação (2007) orienta que:

a escola (especial e comum) ao desenvolver o Atendimento Educacional Especializado deve oferecer todas as oportunidades possíveis para que nos espaços educacionais em que ele acontece, o aluno seja incentivado a se expressar, pesquisar, inventar hipóteses e reinventar o conhecimento livremente. Assim, ele pode trazer para os atendimentos os conteúdos advindos da sua própria experiência, segundo seus desejos, necessidades e capacidades. O exercício da atividade cognitiva ocorrerá a partir desses conteúdos (BRASIL, 2007, p. 24).

Todavia, o AEE ainda não é capaz de oferecer isso aos educandos. Primeiro, os educadores, de modo geral, não estão preparados para compreender o conhecimento cognitivo desse educando e elaborar estratégias de ensino adequadas a eles, visto que, nas Licenciaturas, pouco se estuda sobre os indivíduos especiais. Assim: "Ainda são raros os cursos de licenciatura, e mesmo de Pedagogia, que oferecem habilitação ou disciplinas voltadas às especificidades de alunos com necessidades educativas especiais" (GLAT; PLETSCH, 2004, p. 3). Destarte, salienta-se que os docentes que têm uma formação continuada voltada para essa área são poucos pela falta de tempo ou por falta de recursos financeiros, já que, em muitas vezes, são eles que devem arcar com sua formação continuada. Terceiro, nem todas as escolas têm condições de garantir a acessibilidade para todos envolvidos no processo educacional inclusivo.

Consequentemente, os docentes licenciados, quando se deparam com esse público, sentem dificuldades nos seus planejamentos e nas práticas correspondentes ao ensino especial, ainda mais que o currículo é muito formalista. Quando se trata de deficiência cognitiva e a adultez, Bins (2013) enfatiza a importância de superar o currículo cientificista e formalista exigidos pela Educação e:

perceber o sujeito deficiente intelectual adulto com potenciais para aprender para além da sua constituição neurobiológica e que o processo de aprendizagem ocorre durante toda sua vida, a partir das vivências e experiências individuais e coletivas (BINS, 2013, p. 87). 
Nesse sentido, gestores e docentes são convidados a ter uma formação voltada para o AEE a fim de compreenderem melhor como ocorre a aprendizagem daquele que precisa de práticas diferenciadas para aprender. Para o Ministério da Educação (2003 a 2016) a educação inclusiva requer de quem leciona as seguintes atribuições:

- Participação na elaboração do Projeto Político Pedagógico dos Centros de AEE, construído em interação com os demais membros da comunidade escolar;

- Elaboração, execução e avaliação do Plano de AEE dos estudantes, por meio da identificação de habilidades e necessidades educacionais específicas dos estudantes, definição e organização de estratégias, serviços e recursos pedagógicos e de acessibilidade;

- Realização do atendimento conforme as necessidades específicas de cada estudante, estabelecendo cronograma e a carga horária, individual ou em pequenos grupos.

- Acompanhamento e avaliação da funcionalidade e aplicabilidade dos recursos pedagógicos e de acessibilidade, utilizados pelo estudante, na sala de aula comum e demais ambientes e atividades da escola;

- Planejamento e produção de materiais pedagógicos acessíveis, considerando as necessidades específicas dos estudantes;

- Articulação com os professores do ensino comum, visando à disponibilização de recursos de apoio necessários à participação e aprendizagem dos estudantes;

- Orientação aos professores e às famílias, sobre a utilização dos recursos pedagógicos e de acessibilidade, pelos estudantes, objetivando ampliar o desenvolvimento de suas habilidades, além de promover sua autonomia e independência (MEC, 2003 a 2016, p. 127-128).

Porém, para adequar o currículo, os profissionais envolvidos nesse processo deparam com a escassez de recursos e materiais pedagógicos para trabalhar a Língua Portuguesa, com a falta de tempo e de conhecimento, turmas cheias, espaço físico ruim, busca/pesquisa constante por atividades que não sejam infantilizadas para adaptá-las às especificidades de cada um, com o aprender a não estigmatizar os educandos como "eternas crianças", entre outras. O docente precisa de mais conhecimento científico, de tempo tanto para conhecer o educando, quanto para planejar e elaborar, além de muito respeito pelas diferenças para criar suas 
estratégias de aprendizagem adequadas às demandas de cada um deles. Notadamente, muitas são as demandas no AEE e o docente tenta se capacitar na prática e fazer cursos na área; o Estado não repassa recursos financeiros suficientes para serem investidos em projetos, materiais pedagógicos necessários, melhorar as condições físicas da escola, etc., o que não garante plena acessibilidade a todos os educandos.

\subsection{LÍNGUA PORTUGUESA (LP) NO AEE}

A LP é um instrumento muito importante para que qualquer cidadão brasileiro interaja com o mundo, torne-se independente, saiba se expressar oralmente, saiba escrever bem, saiba interpretar os textos e viver em comunidade. Nesse sentido, o ensino da LP deve oferecer

tanto a possibilidade de desenvolver as competências necessárias para a aprendizagem dos conteúdos escolares, quanto a de aumentar sua consciência em relação ao estar no mundo, ampliando a capacidade de participação social no exercício da cidadania (MEC, 2007, p. 10).

Logo, é importante que o docente de Português adapte o currículo e crie alternativas diferenciadas e flexíveis para atender a necessidade e o interesse de cada educando. A aprendizagem da LP precisa ser significativa para os estudantes. Afinal, o que é isso? De acordo com Ausube|[5] apud Moreira (2010, p. 2) a "aprendizagem significativa é aquela em que ideias expressas simbolicamente interagem de maneira substantiva e não-arbitrária com aquilo que o aprendiz já sabe." Em outras palavras, aquilo que se ensina de novo deve se relacionar com o que o aprendiz já conhece.

\section{COMO OCORRE A PRÁTICA PEDAGÓGICA DE LP NA EJA DA APAE DE MARIANA?}

As turmas da EJA na Apae de Mariana, na Escola Especial Izaltino Teodoro de Almeida Filho, têm, em média, até 14 alunos, com níveis bem diferentes de aprendizagem. Alguns com múltiplas deficiências e outros com graus de déficit cognitivo muito específicos, o que implica na aprendizagem da leitura e da escrita em diversos aspectos e interroga a prática docente constantemente. Embora as turmas 
tenham "poucos" estudantes e nelas haja um monitor e o docente, pressupõe-se que é difícil planejar todas as aulas de LP e atividades diferenciadas para que cada educando tenha uma aprendizagem mais significativa. Ainda, a escola enfrenta seus percalços para encontrar profissionais especializados no AEE. Segundo a pedagoga, em 2016, a Apae passou por dificuldades em relação a contratação de docentes capacitados para atuar na EJA pela falta de formação e experiência com o Ensino Especial. Este ano, a Secretaria Regional de Ensino passou a exigir cursos na área.

As disciplinas de Português, Inglês e Arte passaram a ser ministradas em conjunto, o que possibilitou, ao docente de Português, uma carga horária maior e, assim, a possibilidade de conhecer melhor o educando especial. Em contrapartida, ele não é habilitado em todas as áreas de conhecimento. Jovens e adultos com deficiência intelectual não conseguem avançar na aprendizagem da LP porque não dão conta de assimilar os conteúdos impostos pelo ensino tradicional conservador e homogeneizado. Por isso, o docente da EJA, juntamente com toda a equipe escolar, tem que adaptar o currículo para garantir um ensino de qualidade no AEE. Nesse sentido, os objetivos propostos pela escola para tal modalidade são:

Possibilitar o desenvolvimento de cada aluno segundo seu próprio ritmo;

Contribuir para o seu desenvolvimento global, oferecendo flexibilidade para adaptações do currículo e do material didático quando necessário;

Promover o desenvolvimento de sua competência social (PPP, 2014, p. 21).

Uma das estratégias que o corpo docente usa para facilitar a aprendizagem da Língua Portuguesa é desenvolver trabalhos temáticos com projetos que são pensados no início do ano letivo pela equipe escolar. Um dos projetos desenvolvidos pela escola é o da "Cozinha Experimental". O docente de Português trabalha a leitura e a escrita do gênero receita e, em seguida, os estudantes são direcionados à cozinha para terem a aula prática da receita estudada. São incluídos, também, no planejamento, os textos que abordam temas transversais ${ }^{[6]} \mathrm{e}$, de maneira contextualizada com $\circ$ que 0 aprendiz já conhece, a fim de favorecer a assimilação dos conteúdos. Os conteúdos propostos são desenvolvidos em espaços propícios e com recursos demandados 
pelas oficinas laborais como: a culinária, a horta, a jardinagem, o artesanato, o sorvete, o picolé, a fabricação de temperos, etc. Desse modo, os conteúdos são trabalhados de forma prática, possibilitando, ao educando, a oportunidade de, também, manipular os materiais.

Havendo essa relação do concreto com o abstrato, fica mais acessível deles terem o conhecimento da língua oral ou escrita e, assim, ganharem confiança frente a seus familiares. Além do projeto citado, neste ano, foram desenvolvidos os projetos "Brincando com as palavras - Criando poesias" e o projeto "A história de Mariana abordada no currículo escolar dos estudantes da EJA - anos finais de ensino". Os objetivos desses projetos foram aproximá-los das práticas da cidadania, oportunizando o acesso ao mundo letrado, construindo, pouco a pouco, o processo de alfabetização e letramento de uma forma prazerosa e lúdica, além disso, insere-se o jovem e o adulto no contexto da sociedade, valorizando sua cultura e seu conhecimento cognitivo.

Alguns desses projetos envolveram a participação de escritores e pintores de Mariana que foram até à escola apresentar seus trabalhos e fazer algumas atividades com os educandos. Também foram realizadas visitas a museus da cidade, por exemplo, à casa de Alphonsus de Guimarães ${ }^{[7]}$. Durante a realização dos projetos, os estudantes foram gradativamente desenvolvendo habilidades de memorização de poesia, habilidades de leitura e escrita, habilidades comunicativas, cada educando de acordo com seu próprio ritmo. Foram feitas, também, pinturas diversas em pequenas telas, riscadas com imagens de algumas igrejas da cidade de Mariana, alguns deles expressaram algo indizível, cada um com o seu jeito particular de aprender pintava a sua tela. Conforme a pedagoga, após a implantação da modalidade da EJA na escola, nota-se que os estudantes têm muito interesse pela aprendizagem da Língua Portuguesa, estão mais comunicativos e participativos nas atividades escolares.

Ademais, uma das dificuldades enfrentadas para garantir a aprendizagem dos educandos é a falta de materiais didáticos para trabalhar com a EJA, cabendo, ao docente, pesquisar e fazer as adaptações necessárias das atividades, o que demanda tempo, dedicação, conhecimento e compreensão para planejar cada aula. A escola 
disponibiliza as impressões de materiais, laboratório de informática, materiais de papelaria, materiais reciclados, etc. A estrutura física da escola não é muito boa, porque as salas de aula são muito pequenas e inadequadas para o ensino, visto que seguem os mesmos padrões das salas de aula da escola comum e não têm uma estrutura adequada para o AEE. Além disso, atualmente, há nenhuma sala de recursos com equipamentos disponíveis para oferecer um apoio ao profissional docente. No que tange aos recursos financeiros, boa parte são levantados com os trabalhos desenvolvidos na própria escola como: o artesanato, o brechó, o sorvete, a horta, etc.

Há seis anos, é realizado o "Tropeirão da Apae", que tem, como meta, levantar recursos para ajudar a manter a escola em algum aspecto, ainda que seja uma escola com intervenção municipal. Esses recursos não são suficientes para garantir plena qualidade no AEE durante todo $O$ ano letivo. Contudo, todos os profissionais envolvidos no processo de ensino e aprendizagem dos estudantes da Apae seguem aprendendo na prática, tentando aprimorar e adequar o currículo sempre respeitando as limitações de cada um.

\section{CONSIDERAÇÕES FINAIS}

O desenvolvimento do presente estudo propôs uma reflexão acerca de como o ensino da Língua Portuguesa pode ser trabalhado com estudantes da EJA e sobre a conduta do docente ao desempenhar o seu papel no AEE. Foi possível fazer uma pesquisa de campo para coletar dados mais consistentes acerca de como uma escola pode desenvolver esse trabalho, considerando a adultez dos aprendizes, respeitando os limites, o tempo e o modo de como cada um aprende os conteúdos. É importante que o educador da EJA esteja disposto a se preparar para encarar os desafios da educação inclusiva, que reveja suas práticas de ensino, com profissionalismo e disposição e esteja aberto para formação continuada nessa área. O que se percebe é que há pouca formação específica para a educação inclusiva, fazendo com que o docente busque por conta própria seu percurso formativo. A escola da Apae tem se valido do campo pedagógico dos projetos. 
Os projetos que a escola tem proposto durante o ano letivo são importantes e servem como um guia para o docente planejar as suas práticas pedagógicas de ensino de forma contextualizada e interacionista. De modo geral, os desafios na educação inclusiva se repetem. A falta de recursos financeiros, materiais pedagógicos, investimentos na formação do profissional docente, espaços físicos inadequados acabam comprometendo a qualidade do ensino em algum aspecto. Apesar disso, os profissionais da Apae-Mariana têm se esforçado para garantir o ensino de qualidade, independente do grau de dificuldade e limitações de cada educando, visando-se tornálos mais entrosados na vivência escolar. Os dados apontam a importância de se criar estratégias de ensino nas quais os aprendizes especiais com déficit cognitivo possam participar em alguma medida. Tais estratégias exigem, do docente, experimentação, diversificação e planejamentos diferenciados.

Percebe-se que não é uma tarefa fácil concretizar os conteúdos ensinados na Língua Portuguesa posto que a língua é abstrata, é tratada por regras alheias à realidade social e, com isso, oferece alto grau de complexidade. Enfim, deve-se possibilitar, ao deficiente cognitivo, a aprendizagem efetiva da língua, porém, ainda hoje, é um grande desafio para todos os profissionais envolvidos nesse processo.

\section{REFERÊNCIAS}

APAE Brasil. Federação nacional das Apaes. Disponível em: https://apaebrasil.org.br/page/2 . Acesso em 27: out. 2017.

BINS, K. L. G. Adultos com deficiência intelectual incluídos na educação de jovens e adultos: apontamentos necessários sobre adultez, inclusão e aprendizagem. 2013. 118f. Tese (Doutorado em Educação) - Pontifícia Universidade Católica do Rio Grande do Sul, Porto Alegre, RS, 2013.

BRASIL. Decreto no. 3.956, de 8 de outubro de 2001. Promulga a Convenção Interamericana para a eliminação de todas as formas de discriminação contra as pessoas portadoras de deficiência. Diário Oficial da República Federativa do Brasil. 
Brasília, 9 de outubro de 2001. Disponível em: http://www.planalto.gov.br/ccivil_03/decreto/2001/d3956. Acesso em: 22 nov. 2017.

BRASIL. Ministério da Educação. A Consolidação da inclusão escolar no brasil 2003 a 2016. Secretaria de Educação Continuada, Alfabetização, Diversidade e Inclusão Diretoria de Políticas de Educação Especial Esplanada dos Ministérios.

BRASIL. Ministério da Educação. Secretaria de Educação Fundamental. Parâmetros curriculares nacionais: terceiro e quarto ciclos: apresentação dos temas transversais / Secretaria de Educação Fundamental. Brasília: Secretaria de Ensino Fundamental.1998. 436 p.

BRASIL. Ministério da Educação. Secretaria de Educação Fundamental. Proposta Curricular para a Educação de Jovens e Adultos: segundo segmento do ensino fundamental: 5a a 8a série. Introdução. Brasília: Secretaria de Ensino Fundamental. 2002.

ESCOLA ESPECIAL “IZALTINO TEODORO DE ALMEIDA FILHO”. Projeto político pedagógico. Parecer no 632/10. Portaria 1069/210. Município de Mariana. 2014.

FADERS. Fundação de Articulação e Desenvolvimento de Políticas Públicas para Pessoas com Deficiência e com Altas Habilidades no Rio Grande do Sul. Disponível em: http://www.faders.rs.gov.br/. Acesso em: 09 dez. 2017.

GLAT, R.; PLETSCH, M. D. O papel da Universidade frente às políticas públicas para educação inclusiva. Revista Benjamin Constant, n. 29, p. 3-8, 2004.

INCLUSÃO JÁ. Em defesa do direito à educação inclusiva. Disponível em: https://inclusaoja.com.br/legislacao/. Acesso em: 28 out. 2017.

MOREIRA, M. A. O que é afinal aprendizagem significativa? 1 (After all, what is meaningful learning?). Aula Inaugural do Programa de Pós-Graduação em Ensino de Ciências Naturais, Instituto de Física, Universidade Federal do Mato Grosso, Cuiabá, MT, 23 de Abril de 2010. Qurriculum, La Laguna, Espanha, 2012. 
SCHIRMER, C. R. et al. Formação Continuada a Distância de Professores para o Atendimento Educacional Especializado - Deficiência Física. SEESP/SEED/MEC. Gráfica e Editora Cromos: Curitiba. 2007.

SILVA, M. M da. Processo de inclusão no ensino superior: o caso de estudantes com deficiência na Universidade Federal de Ouro Preto. 2016. 251f. Dissertação (Mestrado em Educação) - Instituto de Ciências Humanas e Sociais, Universidade Federal de Ouro Preto, Mariana, MG, 2016.

\section{APÊNDECE DE RODAPÉ}

[3] Realizada em 28 de Maio de 1999. Conforme o portal da FADERS, ela prevê "a eliminação de todas as formas de discriminação contra pessoas portadoras de deficiência e o favorecimento pleno de sua integração à sociedade. Define a discriminação como toda diferenciação, exclusão ou restrição baseada em deficiência $(\ldots)$.

[4] Essa acessibilidade não se trata somente dos espaços físicos da escola. Ela é pensada na sua forma mais ampla. Se trata da valorização e do respeito pelas pessoas com deficiências, sem estigmatizá-las de que fala SILVA (2016).

[5] David Ausubel (1918-2008) graduou-se em Psicologia e Medicina, doutorou-se em Psicologia do Desenvolvimento na Universidade de Columbia, onde foi professor no Teacher's College por muitos anos; dedicou sua vida acadêmica ao desenvolvimento de uma visão cognitiva à Psicologia Educacional.

[6] “(...) as questões da Ética, da Pluralidade Cultural, do Meio Ambiente, da Saúde, da Orientação Sexual e do Trabalho e Consumo" (MEC, 1988, p. 17).

[7] Alphonsus de Guimaraens, pseudônimo de Afonso Henrique da Costa Guimarães (Ouro Preto, 24 de julho de 1870 - Mariana, 15 de julho de 1921) foi um escritor brasileiro.

Enviado: Setembro, 2020. 
Aprovado: Novembro, 2020. 